\title{
SUPER FINISHING OF GEAR TOOTH PROFILE USING PROFILE GRINDING
}

\section{P. JEYARAMAN \& B. R. ARAVINDHRAJ}

Assistant Professor, Department of Mechanical Engineering, Veltech Rangarajan

\author{
Dr. Sagunthala R\&D Institute of Science and Technology, Avadi, Chennai, Tamil Nadu, India
}

\begin{abstract}
Gears are one of the main power transmitting components in an automobile. So while the transmitting power due to surface roughness on meshing gears there produces unwanted sounds in gearbox and can also disturb the functioning of gearbox. Hence finishing or removal of that unwanted roughness from the gear is done using grinding. Normal grinding process cannot grind the surface between the tooth profile hence an alternative and effective method is used to grind the surface between tooth of gear. Then the grinding wheel is just touched to the surface of the gear and both the gear and grinding wheels are rotated at same rpm. The process of Profile grinding is that provides great potential with respect to flexibility and quality, and variety of gears are used for gring. Thus profile grinding is not only used in job shop applications apart from this if has lot of applications like threaded wheel grinding; e.g., large-module gears. This grinding wheel is used, The cutting speed to be perform and rotates with gear and helix angle. If the gear is helical, A discontinuous pitch movement to grind all teeth it requires a continuous rotational movement in order to follow the lead.
\end{abstract}

KEYWORDS: Gears, Roughness, Grinding \& RPM

Received: May 16, 2018; Accepted: Jun 06, 2018; Published: Jun 29, 2018; Paper Id.: IJMPERDAUG201816

\section{INTRODUCTION}

Gears are the most important mechanical device and main transmitting component of any transmitting system. It provides great potential with respect to flexibility and quality from Profile grinding is one of the process, and can be used to grind a wide variety of gears.

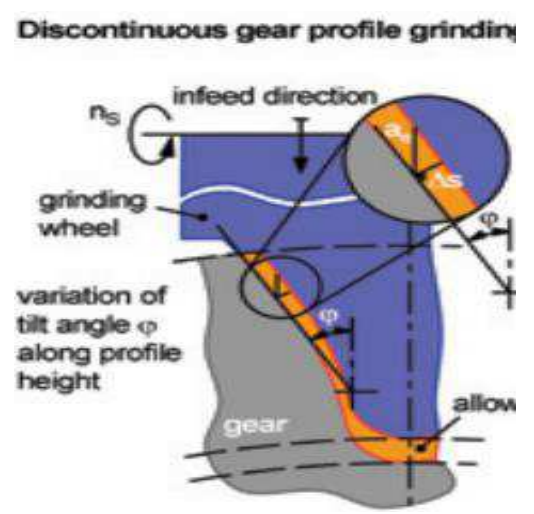

Figure 1: Theoretical Outline of Profile Grinding

Gears are one of the main power transmitting component in an automobile. So while the transmitting power due to surface roughness on meshing gears there produces unwanted sounds in gearbox and can also disturb the functioning of gearbox. Hence finishing or removal of that unwanted roughness from the gear is done using 
grinding. Normal grinding process cannot grind the surface between the tooth profile hence an alternative and effective method is used to grind the surface between tooth of gear. Then the grinding wheel is just touched to the surface of the gear and both the gear and grinding wheels are rotated and material removal is done. Modern gearboxes are characterized by high torque load demands, low running noise and compact design. In order to fulfil these demands, profile modifications are being applied more often than in the past. One of this method is by doing profile crowning, in this method where a constantly increasing amount of material is removed in the transverse section in the direction of the tip and root circle, starting at the middle of the calculated tooth flank length. Points A, E and the value Ca define the arc-like progression. Ca $=\mathrm{C} \alpha \mathrm{a}=\mathrm{C} \alpha \mathrm{f}$ applies for profile crowning. Eccentric profile crowning can be used for different crowning at the tip and root.

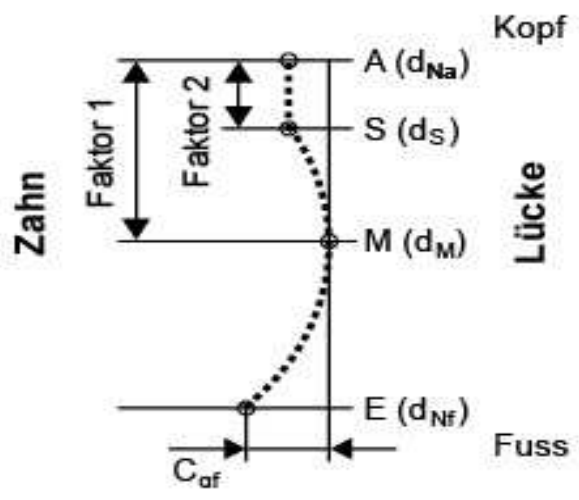

Figure 2: Profile Crowning

\section{PROBLEM INDENTIFICATION}

- During transmission mechanism Gear Box, assemblies and hence quality of its components(referring to gears) play a vital role in the profile grinding.

- Hobbing, Shaving, Heat Treatment processes, etc like this process have occurred and still do occur during the processing of gears especially in areas of and best trials have been carried out so as to attain authentic solutions to the complexities occurred.

- High torque load demands, low running noise and compact design like this modern gearboxes are characterized. In order to fulfill these requirements, the elements used for transmitting power and motion profile specifications have to be tightly controlled and also gears are transmitting.

\section{WHAT IS PROFILE GRINDING?}

- Grinding is an abrasive machining process in which the surface roughness of any material can be removed using a grinding wheel.

- Profile grinding is a technique similar to grinding in which the surface profile between the tooth is grinded. In this technique the grinding wheel is inducted with the inverted profile of gear to be grinded and set at a tilted position with respect to the work piece here gear.

- When both ie. Grinding wheel in contact with gear runs at same rpm then the abrasive nature of the grinding wheel remove the unwanted roughness material and give a surface finish of size in micron. 

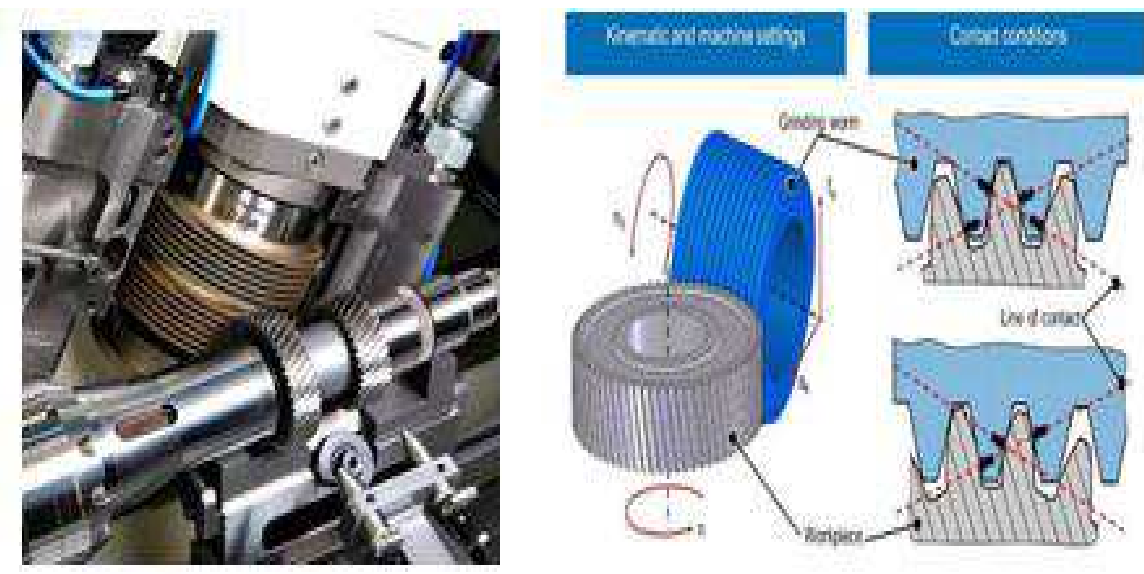

Figure 3: Schematics and Actual Representation of Profile Grinding Setup

\section{GRINDING WHEEL}

The use of CBN tools is characterized by its high process stability. Over their long tool life the geometric quality of the workpiece is virtually unchanged between replatings. Complex workpieces often allow only small tool diameters. Sintered alumina tools are becoming an increasingly viable alternative to plated CBN tools. They now allow cutting speeds up to $60 \mathrm{~m} / \mathrm{s}$. With these speeds, grinding performance almost identical to CBN can now be obtained. Even with the added expenditure for dressing, tool costs per part are signicantly lower.

\section{ADVANTAGES}

\section{Grinding perfomance at CBN Level}

Dressable tools have the advantage of a higher grit density compared to galvanically plated tools. This permits the use of higher axial feed rates. However, the stiffness of dressable tools is considerably lower than for CBN tools with their steel core. Therefore, in general, one additional pass is required (roughing-semifnishing). The higher permissible axial feed rates compensate for this to achieve grinding performance similar to $\mathrm{CBN}$.

\section{Mono-Worm}

Spiral length available within the shift range of a grinding worm determines long tool life. For this, a mono-worm offers the best solution. The ideal diameter to length ratio of the worm is approx. $180 \mathrm{~mm}$ diameter and $200 \mathrm{~mm}$ length. With this relatively small diameter and long worm length, short grinding times and excellent tool life are achieved.

\section{Long Tool Life}

The diameter of a new worm is $195 \mathrm{~mm}$ and can be dressed to approx. $160 \mathrm{~mm}$. For an average automotive transmission gear, this results in approx. 100 parts per dressing cycle and a total output of 10,000 parts per worm

\section{ECONOMICAL}

\section{Profile Grinding with Sintered Alumina}

The diameter of a new worm is $195 \mathrm{~mm}$ and can be dressed to approx. $160 \mathrm{~mm}$. For an average automotive transmission gear, this results in approx. 100 parts per dressing cycle and a total output of 10,000 parts per worm. 
Table 1

\begin{tabular}{|l|l|}
\hline Part693 & \\
\hline Number of teeth & 41 \\
\hline Face width & $2.25 \mathrm{~mm}$ \\
\hline Stock/flank & $14.5 \mathrm{~mm}$ \\
\hline Cutting speed & $0.10 \mathrm{~mm}$ \\
\hline Feed rate & $60 \mathrm{~m} / \mathrm{s}$ \\
\hline Machining time & $0.35 \mathrm{~min}$ \\
\hline
\end{tabular}

\section{HIGH FLEXIBILITY}

Highest flexibility is achieved since each tooth forms and profile modification with a single disc and parameter NC program Showing flexibility

Table 2

\begin{tabular}{|l|l|}
\multicolumn{2}{c}{ EXAMPLE MACHINERY PLANET GEAR } \\
\hline Number of teeth & 30 \\
\hline Module & $4.60 \mathrm{~mm}$ \\
\hline Face width & $63 \mathrm{~mm}$ \\
\hline Stock/flank & $0.14 \mathrm{~mm}$ \\
\hline Cutting speed & $60 \mathrm{~m} / \mathrm{s}$ \\
\hline Feed rate & $1500-2000 \mathrm{~mm} /$ minute \\
\hline Machining time & $3.40 \mathrm{~min}$ \\
\hline
\end{tabular}

\section{TYPES OF DRESSING}

conventional dressing

- profile modifications generated by dressing disc geometry

- limited fexibility

short dressing time

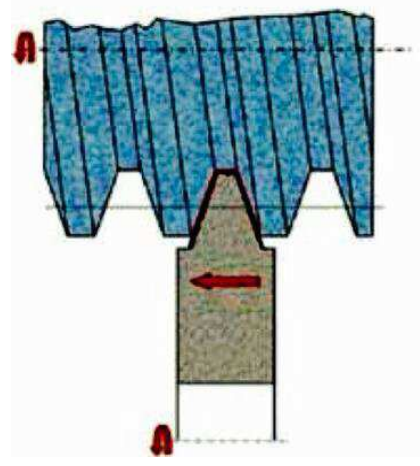

contour dressing

profile modifications generated by the machine kinematic

- highest possible fexibility

long dressing time

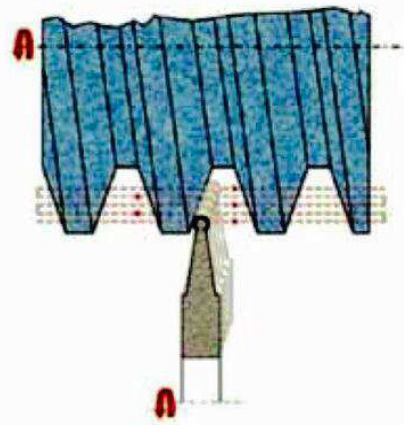

Figure 4

\section{CONVENTIONAL DRESSING}

- In profile grinding process two different dressing principles which can be used. 
- The shape of the profile modification must be known when designing and producing such a dressing disc and the left-hand side shows the most common method, using dressing discs that are copying their shape into the rack profile.

- The flexibility of such a dressing tool is very limited and, in principle, can only be used for one type of gear but the profile on the left and right flank includes a tip relief as well as a slight profile crowning. The dressing operation is relatively short $(3.9 \mathrm{~min})$ due to the line contact between the dressing tool and the grinding wheel.

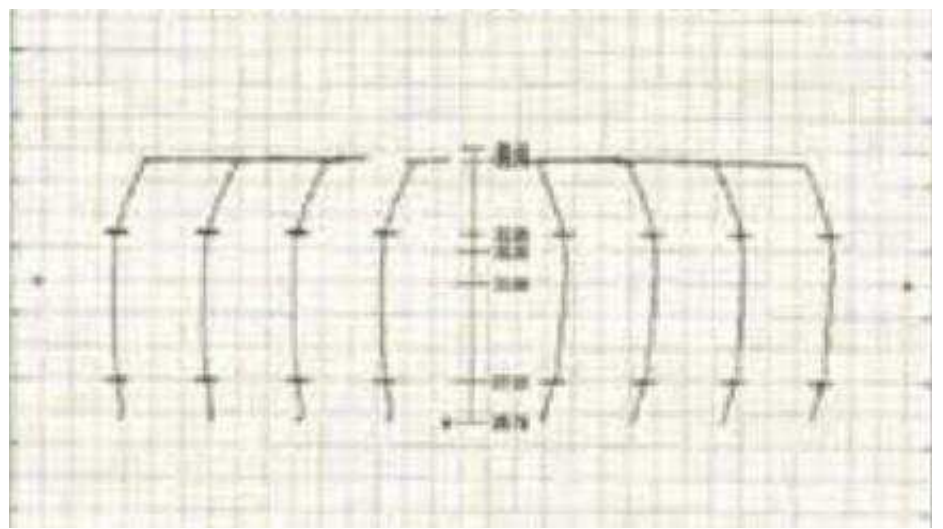

Figure 5: Graph Showing the Dressing using Conventional Dressing Method

\section{CONTOUR DRESSING}

- A dressing tool is used that is generating the required wheel shape by NC motions Contour dressing, shown on the right-hand side of Figure, can be used to achieve the highest possible flexibility.

- The wheel rack profile is the shape of the dressing disc itself is independent. This opens a wide area for profile modifications, but on the other hand, the dressing operation needs much longer dressing time. The required profile was defined by so-called $\mathrm{K}$-charts and was programmed using the machine interface. Such a contour dressing cycle needs about 30-40 minutes, compared to 4-5 minutes for conventional dressing in normal dressing conditions. So the advantage of contour dressing is offset by longer dressing times. A typical result using contour dressing is shown in Figure.

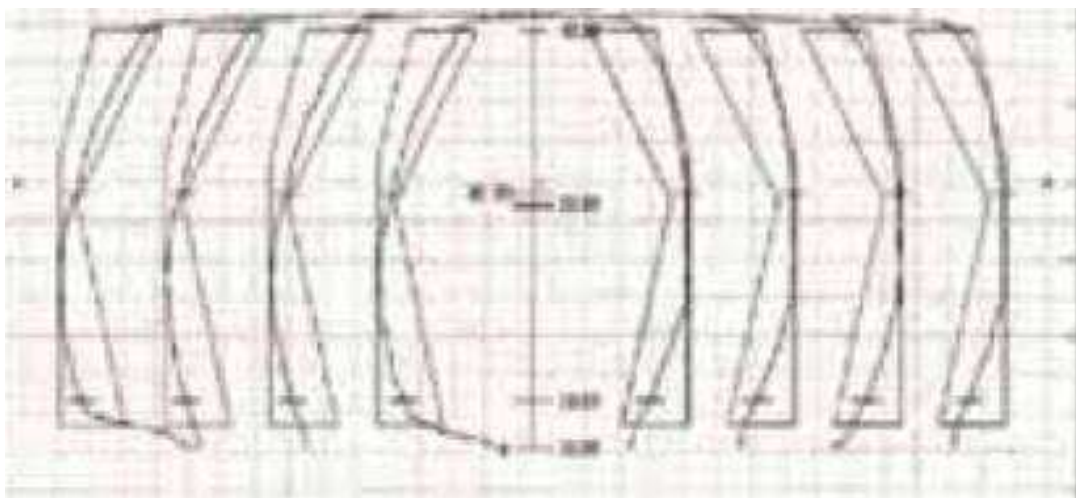

Figure 6: Graph Showing Dressing using Contour Dressing

\section{REDUCED DRESSING TIME IN CONTOUR DRESSING}

- When the right flank side and left flank side dressing value are entered together using a computer interface and 
then dressed together with an increase feed rate of dressing tool there was a phenomenal decrease in dressing time and giving almost the same efficient dressing effect as dressing right and left flanks of the wheel individually

Table 3: First Grinding Wheel

\begin{tabular}{|l|l|}
\hline $\begin{array}{l}\text { Time taken before } \\
\text { interfacing both flanks } \\
\text { together at a time(in min) }\end{array}$ & $\begin{array}{l}\text { Time take after } \\
\text { interfacing both the } \\
\text { flanks together at a } \\
\text { time(in min) }\end{array}$ \\
\hline 1) 37 & 15 \\
\hline 2) 43 & 15.45 \\
\hline 3) 39.25 & 16 \\
\hline 4) 38.33 & 18 \\
\hline 5$) 40$ & 15.5 \\
\hline 6) 40.01 & 16 \\
\hline 7$) 40$ & 17 \\
\hline 8) 39 & 17 \\
\hline
\end{tabular}

Table 3: Second Grinding Wheel

\begin{tabular}{|l|l|}
\hline $\begin{array}{l}\text { Time taken before } \\
\text { interfacing both flanks } \\
\text { together at a time(in min) }\end{array}$ & $\begin{array}{l}\text { Time take after } \\
\text { interfacing both the } \\
\text { flanks together at a } \\
\text { time(in min) }\end{array}$ \\
\hline 1) 37 & 20 \\
\hline 2$) 34$ & 18 \\
\hline 3$) 43$ & 21 \\
\hline 4$) 40$ & 22 \\
\hline 5$) 42$ & 21 \\
\hline 6$) 40$ & 17 \\
\hline 7$) 40$ & 18 \\
\hline 8$) 40$ & 18 \\
\hline
\end{tabular}

\section{CHANGES MADE AND OUTCOMES}

First, For this profile grinding and grinding wheel is adjusted behind the grinding zone well-aimed coolant nozzle with a small orifice was added. (A coolant velocity that doesn't sufficiently cool the workpiece working with large orifices can cause large pressure drops in the coolant-delivery system.) The wheel velocity of coolant velocity the grinding operation to be atched.

\section{CONCLUSIONS AND RESULTS}

- Hence a good surface finish ranging from $40 \mu \mathrm{m}-200 \mu \mathrm{m}$ is obtained depending upon the requirements of the applications of gear positively under a gear tooth profile. 
- The profile and lead graph are obtained once the finishing is done and checked. The profile and lead graph of a gear piece is obtained which shows that the finishing obtained is under the nominal length which is the requirement.

- The graph are obtained on Wenzel's TGear tester which is a mechatronic measuring instrument with a probe controlled by numerical and hence the pitch and runout test graph are obtained to find out whether the turnouts are effectively removed or not. The graph shows that turnouts are removed effectly.

\section{REFERENCES}

1. Posa. J, Barkhausen Noise Measurement In Quality Control And Grinding Process Optimisation In Small Batch; July 2, 2001.

2. Türich A, Werkzeug Profile. Hannover,2002.

3. The Greind; Eric Thomas.

4. The Grinding Wheel: Textbook Of Modern Grinding Practice Kenneth Lewis.

5. Geartechnology.Com

6. Chlattmeier, H. DiskontinuierlichesZahnflankenprofilscheifenmitKorund, Dissertation, RWTH Aachen, 2003.

7. Linke, H. and F. Lierath. Toleranzen and messunsicherherheitenbei der beurteilung von abweichungen an modifiziertenzahnflanken, FVA Forschungsreportzum Vorhaben Nr.376 I+II, FVA - Infotagung Wurzburg, 14./15.

8. Turich, A. Werkzeugprofilerzeugungfur das Verzahnungsschleifen, Dissertation, Universitat Hannover, 2002. 
